que é dificil julgar os erros por negligência, imperícia ou imprudência. Defendem a importância das anotações em prontuário, ainda que tenham dúvidas quanto ao conteúdo e forma, bem como preocupações referentes à sua interpretação e extravio. Diante dos problemas iatrogênicos se vêem emocionalmente perturbadas devido ao conflito ético gerado em relação às suas responsabilidades pessoais e profissionais. Relatam a falta de apoio dos órgãos de classe, da falta de respeito das politicas das instituições de saúde, e dos "boicotes" ao profissional pois entendem que são vistas como problemas à medida que denunciam.

\author{
ESCRAVAS DO RISCO: BIOÉTICA, MULHERES E AIDS \\ SLAVES OF PERIL: BIOETHICS, WOMEN AND AIDS \\ ESCLAVAS DEL RIESGO: BIO-ÉTICA, MUJERES Y EL SIDA
}

Autora: Dirce Guilhem

Orientadores: Volnei Garrafa; Débora Diniz

RESUMO: Esta tese analisa os componentes morais relacionados à mudança do perfil epidemiológico de gênero da epidemia da Sindrome de Imunodeficiência Humana (HIV/Aids). A pesquisa empírica foi realizada com dois grupos de pessoas: gestantes cadastradas em programas de acompanhamento pré-natal e equipes de saúde que as assistiam. Durante o trabalho de campo, quando foram coletados dados quantitativos e etnográficos, foi possivel apreender os valores morais associados à crescente feminização da epidemia, principal objeto desta tese. Os resultados demonstraram que, além das causas epidemiológicas tradicionalmente consideradas pelos formuladores de politicas públicas de saúde, a principal causa de exposição ao risco entre as mulheres são os valores morais relacionados à conjugalidade, onde a crença na segurança do casamento é o fator que mais intensamente as expõe a um estado permanente de vulnerabilidade. No atual momento da epidemia, a confluência entre valores morais e conjugalidade transforma as mulheres em escravas do risco, determinando que as politicas de intervenção nesta realidade necessariamente considerem as crenças morais ligadas à conjugalidade como principal fator de exposição ao risco.

\title{
CUIDANDO CONSTRUTIVAMENTE DE ENFERMEIROS QUE VIVENCIAM SENTIMENTOS DE DESVALORIZAÇÃO: DESVELANDO QUESTÕES EXISTENCIAIS ENTRE O AGIR ÉTICO E O TÉCNICO DA PROFISSÃO
}

\author{
CUIDANDO CONSTRUCTIVAMENTE A ENFERMEROS QUE VIVENCIAN SENTIMIENTOS \\ DE DESVALORIZACIÓN: SE DESVELAN CUESTIONES EXISTENCIALES ENTRE LA \\ ACTUACIÓN ÉTICA Y LA TÉCNICA DE LA PROFESIÓN
}
CARING FOR NURSING PROFESSIONALS WHO EXPERIENCE THE FEELING OF DISESTEEM: REVEALING EXISTENTIAL ISSUES RELATED TO ETHICAL AND TECHNICAL PROFESSIONAL PRACTICE

Autora: Ana Maria Bellani Migott Orientadora: Zuleica Maria Patrício

\footnotetext{
RESUMO: Este estudo caracterizou-se por uma abordagem qualitativa, estruturada a partir de uma Prática Assistencial desenvolvida na cidade de Passo Fundo - RS, no periodo de julho a agosto de 1999. Teve como objetivos elaborar, aplicar e avaliar um marco referencial (próprio) junto a enfermeiros que vivenciam sentimentos
} 